\title{
Model of Transient Process Where Three-Phase Transducer Feeds Induction Motor Equivalent as a Variable Active-Inductive Load
}

\author{
Nenad Marković, ${ }^{1}$ Slobodan Bjelić, ${ }^{2}$ Jeroslav Živanić, ${ }^{3}$ \\ Violeta Milićcević, ${ }^{4}$ and Zoran Milićević ${ }^{5}$ \\ ${ }^{1}$ Advanced Polytechnic School of Vocational Studies Uroševac, 24 Novembre, 38218 Leposavić, Serbia \\ ${ }^{2}$ Faculty of Technical Sciences, University of Priština, Kneza Miloša 7, 38220 Kosovska Mitrovica, Serbia \\ ${ }^{3}$ Faculty of Technical Sciences Čačak, University of Kragujevac, Svetog Save 65, 32000 Čačak, Serbia \\ ${ }^{4}$ Business College of Vocational Studies, Kralja Petra I 70, 18420 Blace, Serbia \\ ${ }^{5}$ Faculty of Economics, University of Priština, Kolašinska 156, 38220 Kosovska Mitrovica, Serbia
}

Correspondence should be addressed to Nenad Marković; nen.mark74@yahoo.com

Received 12 March 2016; Accepted 18 July 2016

Academic Editor: Yan-Wu Wang

Copyright ( 2016 Nenad Marković et al. This is an open access article distributed under the Creative Commons Attribution License, which permits unrestricted use, distribution, and reproduction in any medium, provided the original work is properly cited.

\begin{abstract}
The paper presents a new approach in the analysis of a transient state in a system where the feeding source is a transducer-IGBT inverter and load is introduced through the induction motor with its $R-L$ parameters. Induction motors with different parameters of powers and power factors are tested. MATLAB simulation of the three-phase inverter that feeds the induction machine has replaced the missing lab equipment with which mathematical model of this system was verified. According to the selected parameters of the inverter and induction machine and through the simulation in the MATLAB program, the results are obtained in the form of diagrams that verify the model of a transient state of the induction machine operation when it operates as a motor which is presented as a variable $R-L$ load. The transient process of the system three-phase bridge inverter whose active-inductive load is the induction machine in the conditions of the change of the load parameters is analyzed. The model of the transient process in the system formed by the inverter in PWM (Pulse Width Modulation) converter and induction machine is developed in the time domain and phase coordinates.
\end{abstract}

\section{Introduction}

When there was a need for the analysis of a wave current in a system in which the three-phase induction motor was fed from a three-phase bridge inverter it appeared that there were no adequate mathematical models of such a system in available literature. The models of three-phase induction motors, mostly derived by Park's coordinate system, are quite common in the literature. However, the mathematical model which unites the processes in the system of polyphase motorpolyphase inverter in the time domain could not be found. Therefore, during the formation of the transient state model an idea emerged to present an induction machine in such system as an active-inductive $(R L)$ load which significantly simplifies the whole process.
The analysis of stationary processes in the inverter during the operation with active-inductive $(R L)$ load can be performed using the different methods. However, for the analysis of the transient states it is necessary to compose differential equations and to implement boundary conditions for each time interval of operation. If the form of phase voltage in the electrical circuit is known, then the inverse Laplace transform applies. By applying the different methods it is possible to determine instantaneous values of currents for each part of the voltage, respectively, independent of some other part during the given time interval, while the substitution of initial conditions in obtained relations is not necessary. The use of thyristors that block the passage in electric circuit of the voltage inverter can simplify its typology since there is no 
need to add capacitance, inductance, and additional thyristor elements for commutation [1].

The induction machines are suitable for operation through the inverter transducers, because the winding insulation of standard induction motors tolerates certain voltage overload but at higher speeds of rotation, that is, higher frequencies; they have higher noise level and additional losses [2-4], which affect the motor output torque, depending on the regulation range of the speed of rotation and power factor correction [5-9]. The induction machines can be connected to transducers for the purpose of asymmetry elimination and electric networks harmonics reduction $[10,11]$.

The paper is organized in the following way: Section 2 describes the operation of the three-phase bridge with activeinductive $R L$ load. Section 3 presents the analysis of the transient processes and the transducer-IGBT inverter is proposed as the feeding source. Section 4 presents the selected example of the three-phase inverter with the frequency of $2000 \mathrm{~Hz}$ and modulations frequency of $50 \mathrm{~Hz}$. Following the presentation of analytical considerations in Section 4 presentation and verification of a model on a selected type of the induction motor are given. The optimal type of the inverter with which the desired correction can be achieved in relation to the power factor and the power of the motor is determined. Section 5 presents the concluding remarks.

\section{Description of the System Transducer- Induction Motor}

The operation of three-phase bridge inverter with activeinductive $R L$ load at given time interval and activation of active valves is described in $[1,12]$, but the type of the receiver, such as induction machine, has not been stated.

Scheme of bridge voltage inverter (Figure 1(c)) is characterized by the fact that each time it activates two oppositely orientated and parallel valves. This is necessary for voltage inverter through load that contains reactive component each time to yield both currents (Figure 1(e)). If in the first semiperiod $\left(0 \leq v \leq v_{2}\right)$ valves $V_{1}$ and $V_{2}$ are open, the load is connected to feeding sources.

In the time moment $v=v_{2}$ valves $V_{1}, V_{2}$ and $V_{3}, V_{4}$ are bridged. For ohm-inductive $R L$ load in the first moment after commutation $\left(v_{2} \leq v \leq v_{3}\right)$, using EMF autoinduction the current retains its direction, and the current of feeding sources changes its sign. After passing through the load, energy returns to the feeding source. Valves $V_{1}-V_{4}$ must be controlled in all time intervals in order to obtain $V_{d}$ voltage. Valves $V_{1}^{\prime}-V_{4}^{\prime}$ can be uncontrolled (diodes). In the interval $v_{2} \leq v \leq v_{3}$ load current (broken line in Figure $1(\mathrm{~d})$ ) passes through inverse diodes $V_{3}^{\prime}$ and $V_{4}^{\prime}$. In order to improve the quality of feeding source of the rectifier, at the input of the inverter it is necessary to add the capacitor of sufficient capacitance; otherwise it would not be able to return the energy from the output circuit of the inverter in the time interval when the inverse diode yields the current.

At ohm-capacitance $R C$ load the control valves $V_{1}$ and $V_{2}$ yield current at the beginning of the first semiperiod, and diodes $V_{1}^{\prime}$ and $V_{2}^{\prime}$ come into operation at the end when current of thyristor comes to zero value [13].
In the conductance interval diodes at controlled valves maintain small negative voltage, equal to direct voltage drop at diodes. During the activation of the following pair of valves $V_{3}$ and $V_{4}$, the source voltage comes to diodes $V_{1}^{\prime}$ and $V_{2}^{\prime}$ in reverse direction, and this results in disconnection of diodes. Simultaneously with disconnection of diodes the direct voltage occurs on valves $V_{1}$ and $V_{2}$. Therefore, at ohm-capacitance nature of the load in voltage inverter, generally, partially controllable valves-thyristors can be applied provided that the time, when the voltages on them are negative, is sufficient for blockage $[14,15]$.

Load current $i_{\text {load }}$ for ohm-inductive load can be determined as reaction of load circuits on periodical partially rectangular voltage $u_{\text {load }}$ (Figure $1(\mathrm{e})$ ):

$$
i_{\text {load }}=I_{0}\left[1-\frac{2 e^{-k 9}}{\left(1+a^{3}\right)}\right] \quad(0 \leq v \leq \pi),
$$

where $I_{0}=V_{d} / R_{\text {load }}$ is base value of the current, $k=$ $R_{\text {load }} / \omega L_{\text {load }}$ is load parameter (for polyphase schemes), $R_{\text {load }}$ and $L_{\text {load }}$ are resistance and inductance of a single phase, $v=\omega t$ is independent variable of time angle, and $a=$ $e^{-k \pi / 3}$ is general coefficient.

The basic characteristics of load circuit, source, and equipment that inverter contains are determined according to the values of the parameters of load circuit $k$. The effective value of voltage on load is $V_{\text {load }}=V_{d}$, and effective value of load current is

$$
I=I_{0} \sqrt{1+\left\{\frac{2\left(a^{3}-1\right)}{\left[k \pi\left(a^{3}+1\right)\right]}\right\}} .
$$

Maximum value of load current is

$$
I_{m}=\frac{I_{0}\left(1-a^{3}\right)}{\left(1+a^{3}\right)} .
$$

The passing moment of load current through zero (Figure $1(\mathrm{e})$, point $\left.v_{1}=\sigma\right)$ is

$$
\sigma=\left(\frac{1}{k}\right) \ln \left[\frac{2}{\left(1+a^{3}\right)}\right] .
$$

Mean and effective values of current of inverse diodes in interval $0 \leq v \leq \sigma$ are

$$
\begin{aligned}
I_{V_{\text {mean }}^{\prime}} & =\frac{I_{0}}{2 \pi}\left[\frac{1-a^{3}}{k\left(1+a^{3}\right)}-\sigma\right], \\
I_{V^{\prime}} & =I_{0} \sqrt{\frac{1}{2 \pi}\left[\frac{1+2 a^{3}-3 a^{6}}{2 k\left(1+a^{3}\right)^{2}}-\sigma\right]} .
\end{aligned}
$$

Mean and effective values of current of thyristor in interval $\sigma \leq v \leq \pi$ are

$$
\begin{aligned}
I_{V_{\text {mean }}} & =\frac{I_{0}}{2 \pi}\left[\pi-\sigma-\frac{1-a^{3}}{k(1+a)^{3}}\right], \\
I_{V} & =I_{0} \sqrt{\frac{1}{2 \pi}\left[\pi-\sigma-\frac{3-2 a^{3}-a^{6}}{2 k\left(1+a^{3}\right)}\right]} .
\end{aligned}
$$




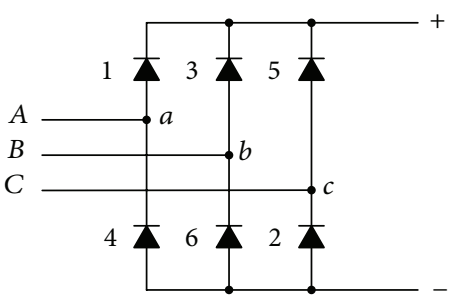

(a)

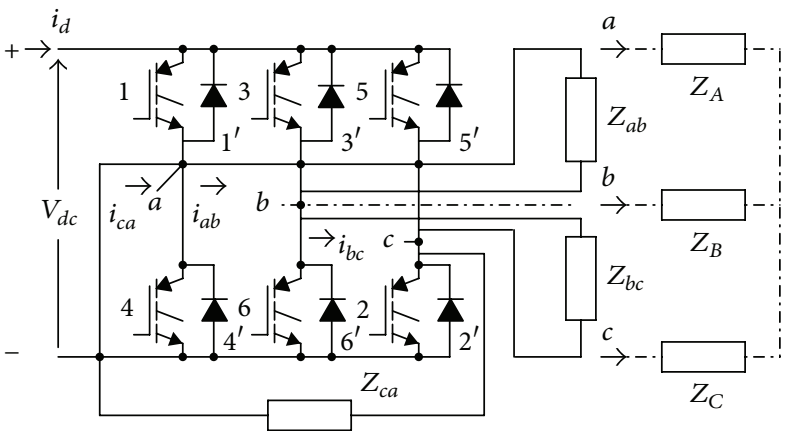

(b)

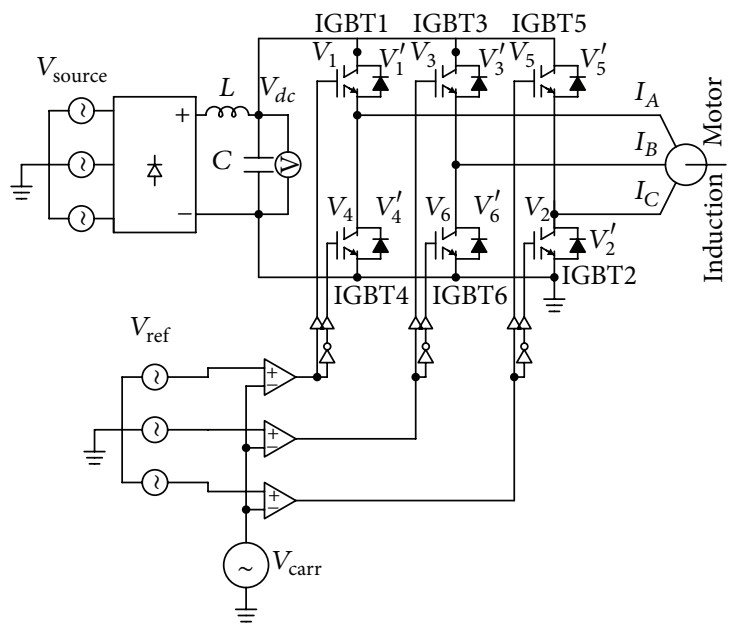

(c)

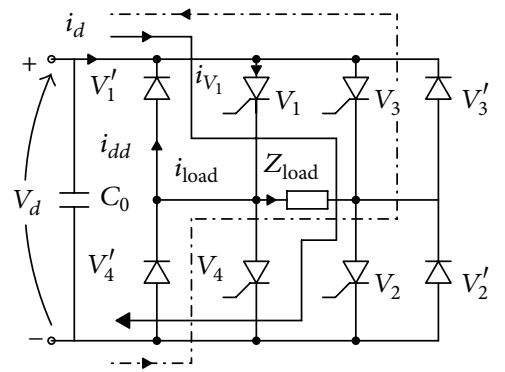

(d)

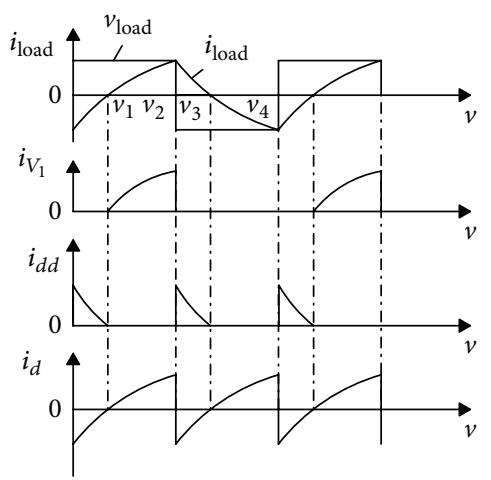

(e)

FIGURE 1: AC-DC-AC converter: (a) diode rectifier, (b) IGBT/diode inverter, IGBT inverter, (c) single phase bridge voltage inverter, (d) full three-phase bridge scheme of inverter, and (e) time diagrams of currents and voltages.

Mean value of current of feeding source is

$$
I_{d}=I_{0}\left[1+\frac{2\left(a^{3}-1\right)}{k \pi\left(1+a^{3}\right)}\right] .
$$

Angle during which thyristor conducts is

$$
\lambda=\frac{\omega \pi}{\omega_{0}}=\frac{\pi}{\sqrt{(1 / F)-\left(B^{2} / 4\right)}},
$$

where $B=1 /(\omega C R)$ is load coefficient and $F=\omega^{2} L L_{d} C /\left(L_{d}+\right.$ $L)$ is frequency coefficient.
Active and apparent power of load are

$$
\begin{aligned}
& P=V_{d} I_{d}=V_{d} I_{0}\left[1+\frac{2\left(a^{3}-1\right)}{k \pi\left(1+a^{3}\right)}\right], \\
& S=V_{\text {load }} I=V_{d} I_{0} \sqrt{1+\frac{2\left(a^{3}-1\right)}{k \pi\left(1+a^{3}\right)}} .
\end{aligned}
$$

Power factor of load is

$$
\cos \varphi_{\text {load }}=\frac{P}{S}=\sqrt{1+\frac{2\left(a^{3}-1\right)}{k \pi\left(1+a^{3}\right)}} .
$$


Voltage and current of load are mathematical functions:

$$
\begin{aligned}
& v_{\text {load }}(v)=\frac{2 V_{d}}{\pi} \sum_{q=1}^{\infty} \frac{\sin q v}{q}\left[1-(-1)^{q}\right], \\
& i_{\text {load }}(v)=\frac{2 V_{d}}{\pi} \sum_{q=1}^{\infty} \frac{\sin \left(q v-\varphi_{q}\right)}{q \sqrt{R_{\text {load }}^{2}+\left(q \omega L_{\text {load }}\right)^{2}}}\left[1-(-1)^{q}\right],
\end{aligned}
$$

where is $\varphi_{q}=\operatorname{arctg}\left(q \omega L_{\text {load }} / R_{\text {load }}\right)$.

For small changes of voltage at the input of capacitor (it has been adopted that $\Delta V_{c} \leq 0.1 V_{d}$ ) and if change of load current is neglected due to voltage changes on capacitor, the instantaneous value of capacitor current is equal to the instantaneous value of load current:

$$
\begin{aligned}
i_{c}(t) & =C_{0} \frac{d u_{c}}{d t}=i_{\text {load }}(t) \\
& =\frac{V_{d}}{R_{\text {load }}}\left(1-\frac{2 e^{-R_{\text {load }} t / L_{\text {load }}}}{1+e^{-R_{\text {load }} T /\left(2 L_{\text {load }}\right)}}\right),
\end{aligned}
$$

whereas capacitance $C_{0}$ is determined with respect to charging time of capacitor:

$$
C_{0}=\frac{V_{d} \tau}{R_{\text {load }} \Delta V_{c}}\left(\frac{1-e^{-T /(2 \tau)}}{1+e^{-T /(2 \tau)}}-\ln \frac{2}{1+e^{-T /(2 \tau)}}\right),
$$

where $u_{c}(t)$ is voltage on capacitor and $\tau=L_{\text {load }} / R_{\text {load }}$ time constant of load circuit.

Required capacitance of capacitor at given quantities $V_{d}$, $R_{\text {load }}, \tau, \Delta V_{c}$ depends on alternating current frequency. The reduction of frequency requires higher capacitance of the capacitor.

\section{Analysis of the Transient Process in the AC-DC-AC Converter System-Induction Motor as RL Load}

The transient processes in three-phase inverters with bridge schemes depend on load characteristics, coupling way of transformer windings, ability to control the inverter, and type of feeding source and inverter scheme $[12,16]$. Figure 2(c) presents the proposed model of the transducer composed of two parts. The first part is three-phase uncontrollable rectifier at bridge connection with $L C$ filter (Figure 2(a)) which corrects alternating voltage $V_{\text {source }}$ of fixed frequency into direct voltage $V_{d c}$. The second part is three-phase autonomous source which uses PWM modulation for regulation of speed of rotation of induction motors $[13,17]$.

The transducer can be set to desired frequency of phase currents of electromotor and thus the number of revolutions, by setting the frequency of control signal. If instead of uncontrollable rectifier the controllable one is used, the voltage $V_{d c}$ can be also set, and time and amplitude of output currents of motor $I_{A}, I_{B}$, and $I_{C}$, and it is possible to control the machine torque of induction motors.

Openings of thyristor correspond to semiperiod $\lambda=180^{\circ}$ and 6 independent signals of opening and closing conditions are possible (on Figure 3(a) numbers denote accomplished state of adequate active thyristors). However, in practice, the angle $\lambda=180^{\circ}$ is not possible. There is an angle of lock of inverting which must not be exceeded because transducer could promptly pass from inverter to transducer operating mode, therefore exposing thyristor to destruction $[16,18]$.

If loads are connected in a star each phase is switched: either parallel to second phase and in line with third or in line with other two phases (those two phases are connected in parallel).

Each phase comes under $V_{d} / 3$ or $2 V_{d} / 3$, and phase voltage on load has a two-stage form.

Modulation index is defined with

$$
m_{\text {index }}=\frac{V_{a b c}(p . u .)}{V_{d \_ \text {ref }}(p . u .)} \text {. }
$$

Star Coupling (Figure 1(b) Broken Line). Effective value of phase voltage is

$$
V_{\text {phase }}=\frac{\sqrt{2} V_{d}}{3} .
$$

The instantaneous value of phase current in separate intervals (Figures 2(b) and 2(c)) is

$$
\begin{aligned}
& i_{A}(v)=\frac{V_{d}\left[1-\frac{(1+a)(2-a)}{3 R} e^{-k v}\right]}{1+a^{3}} \quad\left(0 \leq v \leq \frac{\pi}{3}\right), \\
& i_{A}(v)=\frac{V_{d}}{3 R}\left[2-\frac{(1+a)^{2}}{1+a^{3}} e^{-k v}\right] \quad\left(\frac{\pi}{3} \leq v \leq \frac{2 \pi}{3}\right), \\
& i_{A}(v)=\frac{V_{d}}{3 R}\left[1+\frac{(1+a)(1-2 a)}{1+a^{3}} e^{-k v}\right] \\
& \quad\left(\frac{2 \pi}{3} \leq v \leq \pi\right) .
\end{aligned}
$$

Effective value of load current is

$$
I_{d}=I_{\text {line }}=\frac{\sqrt{2}}{3} I_{0} A,
$$

where $A=\sqrt{1-[3 /(2 k \pi)]\left[\left(1-a^{2}\right) /\left(1-a+a^{2}\right)\right]}$.

$A$ presents a parameter defined by the relation of phase/line current by current $I_{f}=I_{d}$ obtained in the inverter and effective value of load current (the current of induction machine) $I_{0}$.

Since during each interval $\pi / 3$ the corresponding phase is connected in line with feeding source, instantaneous value of current of feeding source is given by expressions (16). The mean value of current of feeding source is

$$
I_{d}=\frac{2}{3} I_{0} A^{2}
$$

Active and full (apparent) powers of load are

$$
\begin{aligned}
& P=V_{d} I_{d}=\frac{2}{3} V_{d} I_{0} A^{2}, \\
& S=3 V_{\mathrm{ph}} I_{\mathrm{ph}}=\frac{2}{3} V_{d} I_{0} A .
\end{aligned}
$$




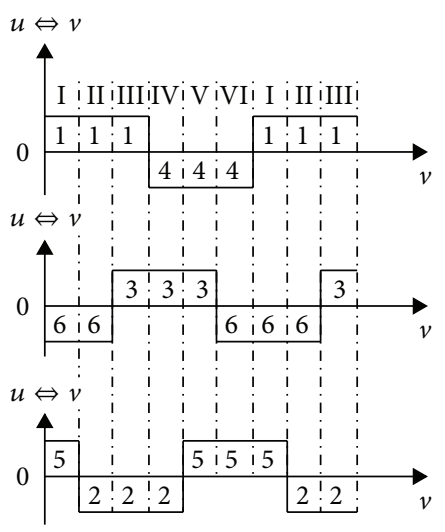

(a)

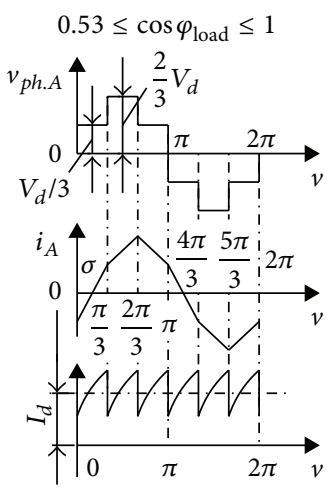

(b)

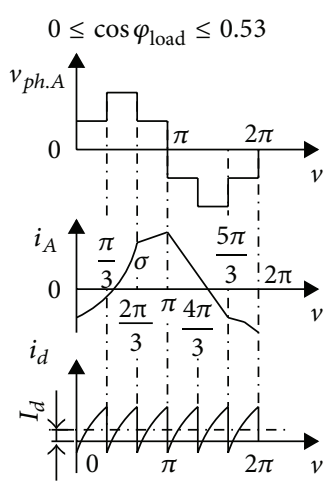

(c)

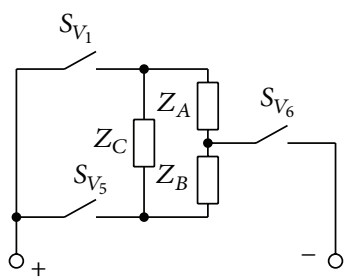

(d)

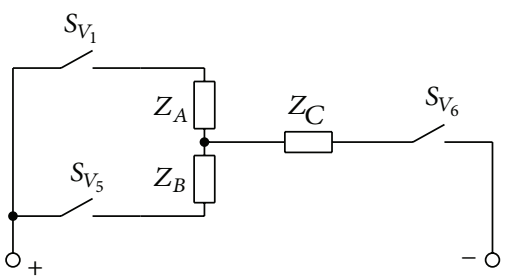

(e)

FIGURE 2: (a) Diagrams of valves operation, (b, c) time diagrams of currents and voltages of three-phase inverter coupled in star and $\lambda=180^{\circ}$, and $(d, e)$ equivalent schemes of loads coupled in delta and star.

Power factor of load is

$$
\cos \varphi_{\text {load }}=\frac{P}{S}=A .
$$

In the moment after the bridging (activation of valve $V_{4}$ and valve $V_{1}$ (Figure $\left.1(\mathrm{~b})\right)$ ), current $i_{A}$ supported by EMF self-induction of that phase has previous direction and flows through valves $V_{1}, V_{5}$ into the phase $C$. Reactive current of phase $A$ becomes a part of the current of the phase $C$ and from the source it takes current lower for a value of that reactive current. If reactive current of bridged phase $A$ (current $i_{A}$ ) is higher than current of phase $C$ (current $i_{C}$ ), then in commutation torque current of feeding source changes its sign.

If the inverter is fed from rectifier, the capacitor $C_{0}$ is placed on its input and receives the reactive load energy and decreases possible overvoltages. The current in the feeding source does not change the direction if the following condition is met:

$$
\left|i_{A}(v=0)\right| \leq\left|i_{C}(v=0)\right|,
$$

which corresponds to load limits $0.53 \leq \cos \varphi_{\text {load }} \leq 1.0$.

For parameters values according to condition (21), load reactive current completely closes down along contour that encompasses phases. When $0 \leq \cos \varphi_{\text {load }} \leq 0.53$, the current of feeding source changes its direction and only a part of reactive current of bridged phase branches into second phase, and the remaining part passes through the feeding source.

Value of the current through capacitor of capacitance $C_{0}$ which is connected to the output of the inverter can be obtained in accordance with (12) and substituting instead of $i_{\text {load }}(t)$ value $i_{A}(t)$ :

$$
\begin{aligned}
i_{c}(t) & =C_{0} \frac{d u_{c}}{d t}=i_{\text {load }}(t) \\
& =\frac{V_{d}}{R_{\text {load }}}\left(1-\frac{2 e^{-R_{l} t / L_{l}}}{1+e^{-R_{l} T /\left(2 L_{l}\right)}}\right), \\
i_{c}(t) & =i_{A}(t)=\frac{V_{d}}{R_{\text {load }}}\left(1-\frac{2 e^{-R_{l} t / L_{l}}}{1+e^{-R_{l} T /\left(2 L_{l}\right)}}\right) .
\end{aligned}
$$

Maximum value of current through operating valves for $0.53 \leq \cos \varphi_{\text {load }} \leq 1.0$ is

$$
I_{m}=\frac{V_{d}}{3 R_{\mathrm{load}}}\left[\frac{(2-a)\left(1-a^{2}\right)}{\left(1+a^{3}\right)}\right],
$$

and for $0 \leq \cos \varphi_{\text {load }} \leq 0.53$ it is

$$
I_{m}=\frac{V_{d}}{3 R_{\mathrm{load}}}\left[\frac{(1+a)\left(1-a^{2}\right)}{\left(1+a^{3}\right)}\right] .
$$

Line current changes its sign at the point $\sigma$ (Figures 2(b) and $2(\mathrm{c}))$. For $\cos \varphi_{\text {load }} \geq 0.53$ it is $\sigma=(1 / k) \ln \left[\left(2+a-a^{2}\right) /(1+\right.$ $\left.\left.a^{3}\right)\right]$ and for $\cos \varphi_{\text {load }} \leq 0.53$ it is $\sigma=(1 / k) \ln \left[\left(1+2 a+a^{2}\right) /(1+\right.$ $\left.\left.a^{3}\right)\right]$.

Current sequencing among active valves and inverse diodes depends on a quantity $\cos \varphi_{\text {load }}$. Current flows through inverse diodes in the interval $0 \leq v \leq \sigma$ and through active valves in the interval $\sigma \leq v \leq \pi$. By integrating the currents 


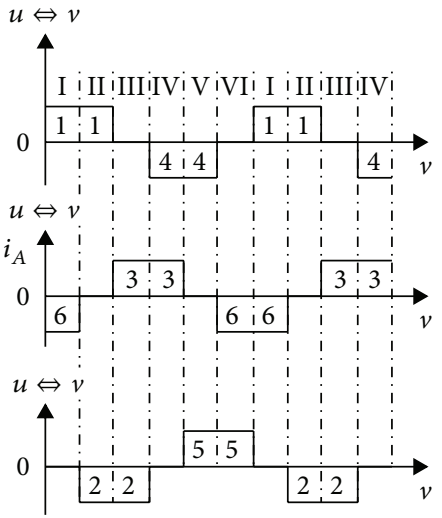

(a)

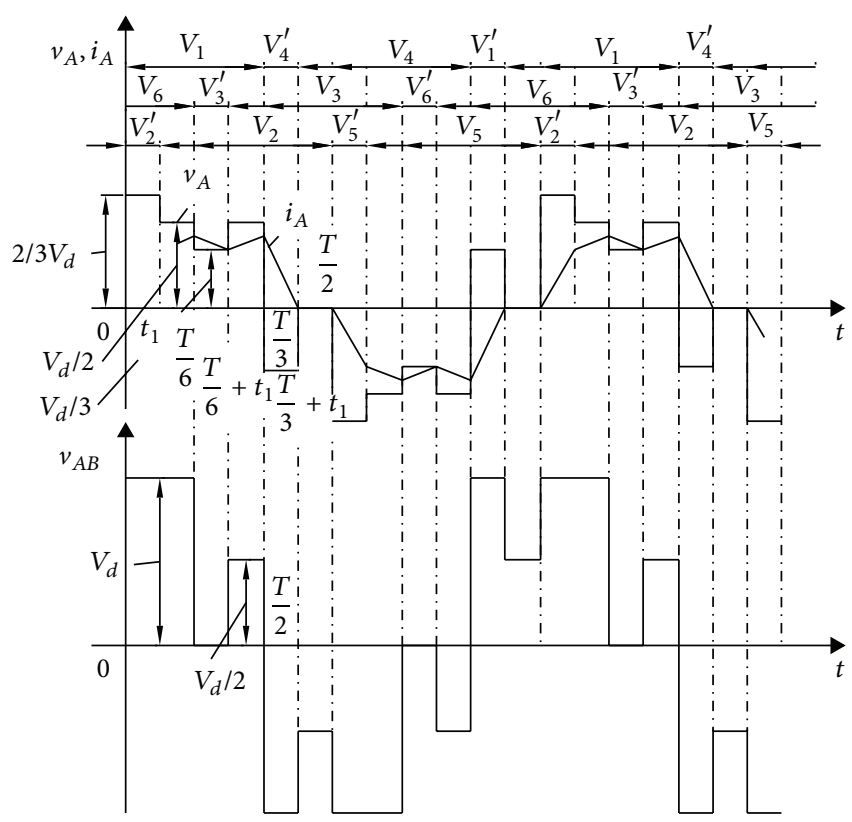

(b)

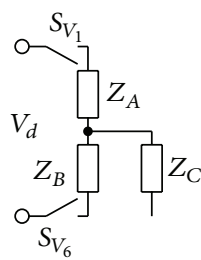

(c)

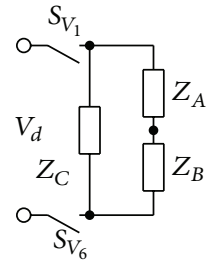

(d)

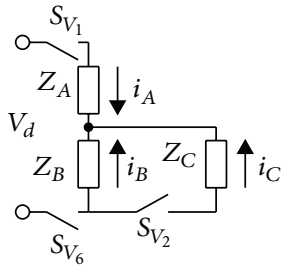

(e)

Figure 3: (a) Diagram of valve operation, (b) time diagram of currents and voltages of three-phase inverter at $\lambda=120^{\circ}$, and (c, d, e) equivalent schemes for different coupling of opened and closed valves.

into these intervals $I_{V_{\text {mean }}}, I_{V}, I_{\text {mean } \cdot d}, I_{d}$ can be obtained for different values of $\cos \varphi_{\text {load }}$.

Delta Coupling (Figure 1(b) Solid Line/Link of Load). Effective value of voltage on load is

$$
V_{\mathrm{ph}}=V_{\text {line }}=\sqrt{\frac{2}{3}} V_{d} .
$$

Instantaneous value of phase currents is

$$
\begin{aligned}
& i_{a b}(v)=\frac{V_{d}}{R_{\text {load }}}\left(1-\frac{1+a}{1+a^{3}} e^{-k v}\right) \\
& \quad \text { za }\left(0 \leq v \leq \frac{2 \pi}{3}\right), \\
& i_{a b}(v)=\frac{V_{d}}{R_{\text {load }}}\left(\frac{1-a^{2}}{1+a^{3}} e^{-k v}\right) \quad \text { za }\left(\frac{2 \pi}{3} \leq v \leq \pi\right) .
\end{aligned}
$$

Phase currents $i_{c a}(t)$ and $i_{b c}(t)$ are determined by angle $v=2 \pi / 3$, and line currents of loads coupled into delta and star correspond to relation $1 / 3 i_{A \Delta}(v)=i_{A Y}(v)$.

Loads of three-phase inverters, as a rule, are induction machines. For analysis of impairment of their characteristics at feeding by nonsinusoidal voltages, examined function develops into harmonic series and determines the influence of each harmonic, respectively $[12,16]$.

If inverter is open during $\lambda=120^{\circ}$ on three-phase bridge inverter only two operating valves are simultaneously open (Figure 3(a)). By changing load parameters the form of voltage also changes. The time diagram is presented on Figure 3(b).

Analysis of schemes (Figures 3(c) and 3(d)) shows that, at ohm load in star connection (Figure 3(c)), if one phase is disconnected and the other two are connected in line, the phase voltage will have rectangular form $V_{d} / 2$ and $\lambda=180^{\circ}$. At ohm load in delta connection (Figure 3(d)) single phase load is connected to voltages $V_{d}$ and $V_{d} / 2$. The phase voltage has two stage forms for $\lambda=180^{\circ}$ as well as for load star coupling. When inverter feeds the induction machine (which presents ohm-inductive load), the phase voltage varies depending on the nature of the load. In the star connection the current $i_{C}$, supported by EMF induction, continues to flow in the same direction until the activation of the valve $V_{5}$ and closes through inverse diode $V_{2}^{\prime}$ and it activates phase $C$ parallel with phase $B$ (Figure 3(e)). If energy, converted in inductance of load phase, is consumed during the time $t_{1}<T / 6$, then current comes to zero in the other two phases (Figure 3(c)). 


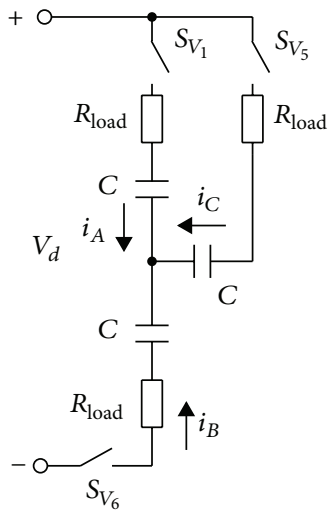

(a)

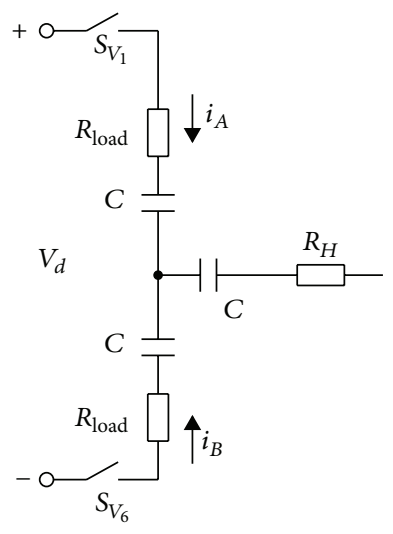

(b)

FIGURE 4: Equivalent schemes of three-phase inverter in operation with ohm-capacitive load.

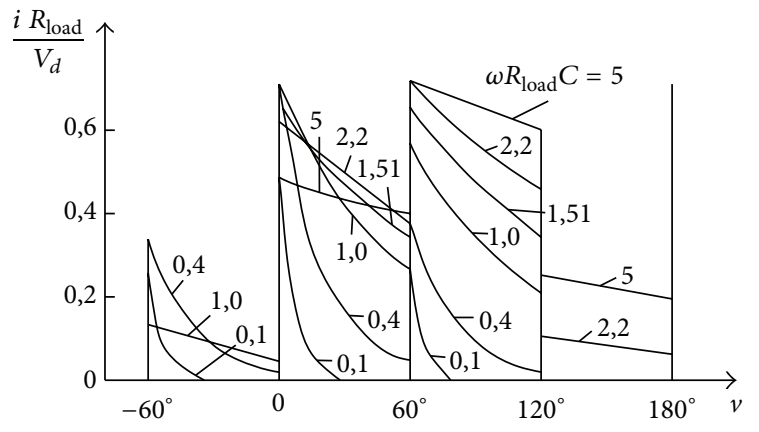

(a)

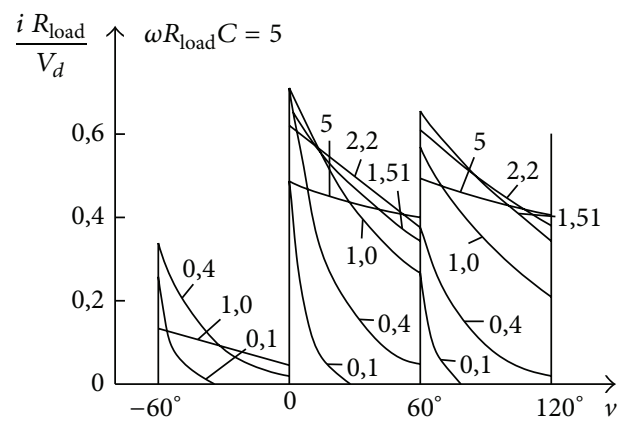

(b)

Figure 5: The diagrams of load current at (a) $\lambda=180^{\circ}$ and (b) $\lambda=120^{\circ}$.

If $\cos \varphi_{\text {load }}, 0.53 \leq \cos \varphi_{H} \leq 1$, then the condition $t_{1}<$ $T / 6$ is achieved. For $\cos \varphi_{\text {load }}<0.53$ the form of phase voltage is the same as in state of permanently connected active valves with angle $\lambda=180^{\circ}$. Currents along load phases in that case correspond to expressions from (16).

If for $\lambda=120^{\circ}$ the passing time of current through inverse diode is denoted with $\Delta t$, the effective value of phase and line voltage is

$$
\begin{gathered}
V_{\mathrm{ph}}=\sqrt{\frac{\pi+\Delta}{6 \pi}} V_{d}, \\
V_{\text {line }}=\sqrt{\frac{\pi+\Delta}{2 \pi}} V .
\end{gathered}
$$

Change of current time flow through inverse diode leads to change from phase to line voltage while at $\lambda=180^{\circ}$ these voltages do not change.

If three-phase inverter feeds the induction motor (ohminductive load) and $\lambda=180^{\circ}$, the form of voltage and substitution scheme in intervals of commutation (intermittent) do not depend on load power factor, but in the case $\lambda=$ $120^{\circ}$ the form of voltage depends on power factor and for $0.53 \leq \cos \varphi_{\text {load }} \leq 1.0$ substitution scheme changes its structure (Figures 3(c) and 3(d)). In connection of inverter and induction motor into star (symmetric ohm-capacitance load) for $\lambda=180^{\circ}$, irrespectively of the load quantity, three valves are always open. Equivalent scheme of the inverter is

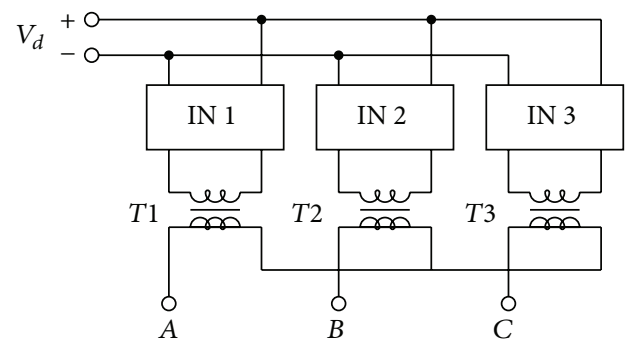

FIGURE 6: The three-phase inverter composed of three single-phase inverters.

given in Figure 4(a), and the form of phase voltage is such that, as for ohm-inductive load (Figures 2(b) and 2(c)), it does not depend on parameters $R_{\text {load }}$ and $C$.

The instantaneous values of phase currents in the interval $0 \leq t \leq T / 6$ are

$$
\begin{aligned}
& i_{A}=\frac{V_{d}}{3 R_{\text {load }}} \frac{2-b}{1-b+b^{2}} e^{-\delta t}, \\
& i_{B}=-\frac{V_{d}}{3 R_{\text {load }}} \frac{1+b}{1-b+b^{2}} e^{-\delta t}, \\
& i_{C}=-\frac{V_{d}}{3 R_{\text {load }}} \frac{1-2 b}{1-b+b^{2}} e^{-\delta t},
\end{aligned}
$$

where $\delta=1 / R_{H} C, b=e^{-(\pi / 3)\left(1 / \omega R_{\text {load }} C\right)}$. 


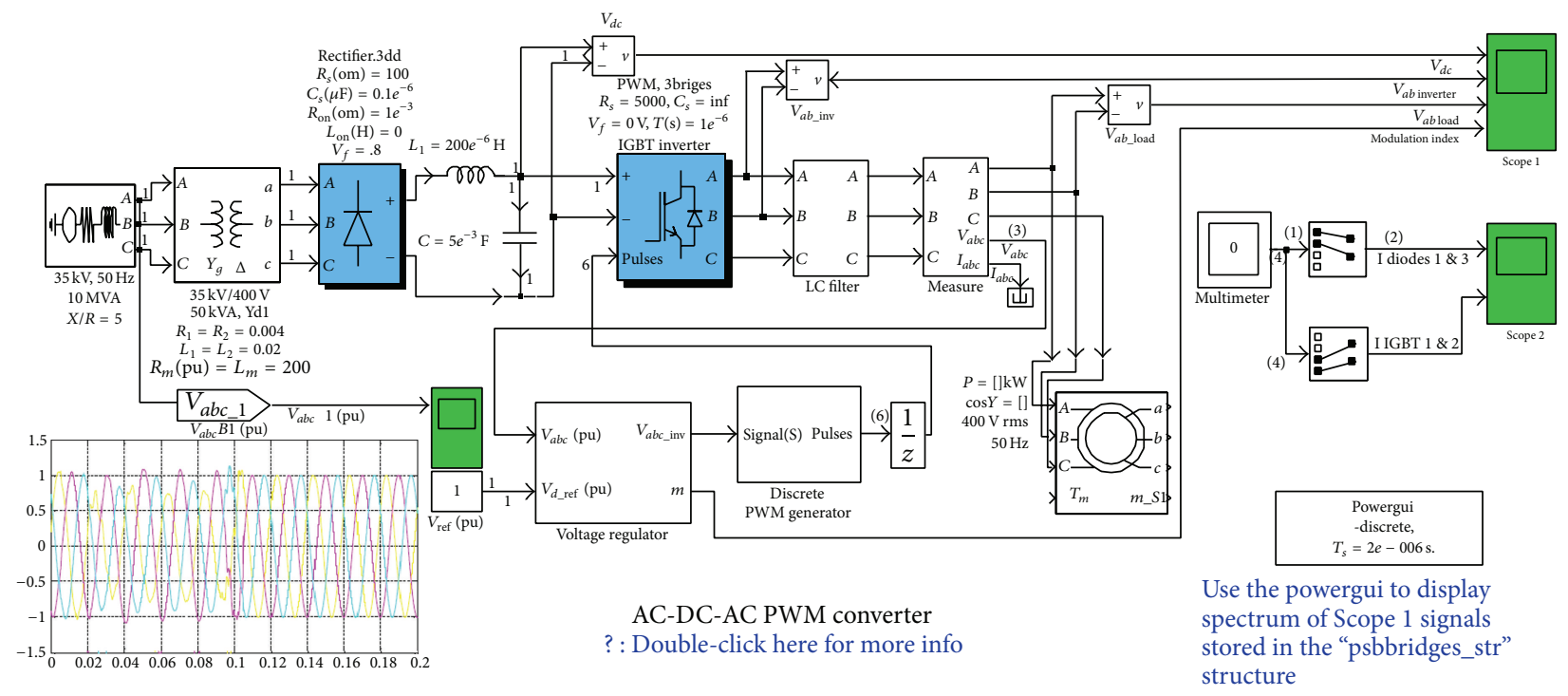

FIGURE 7: Model scheme for simulation of operation of induction motor fed from PWM converter.
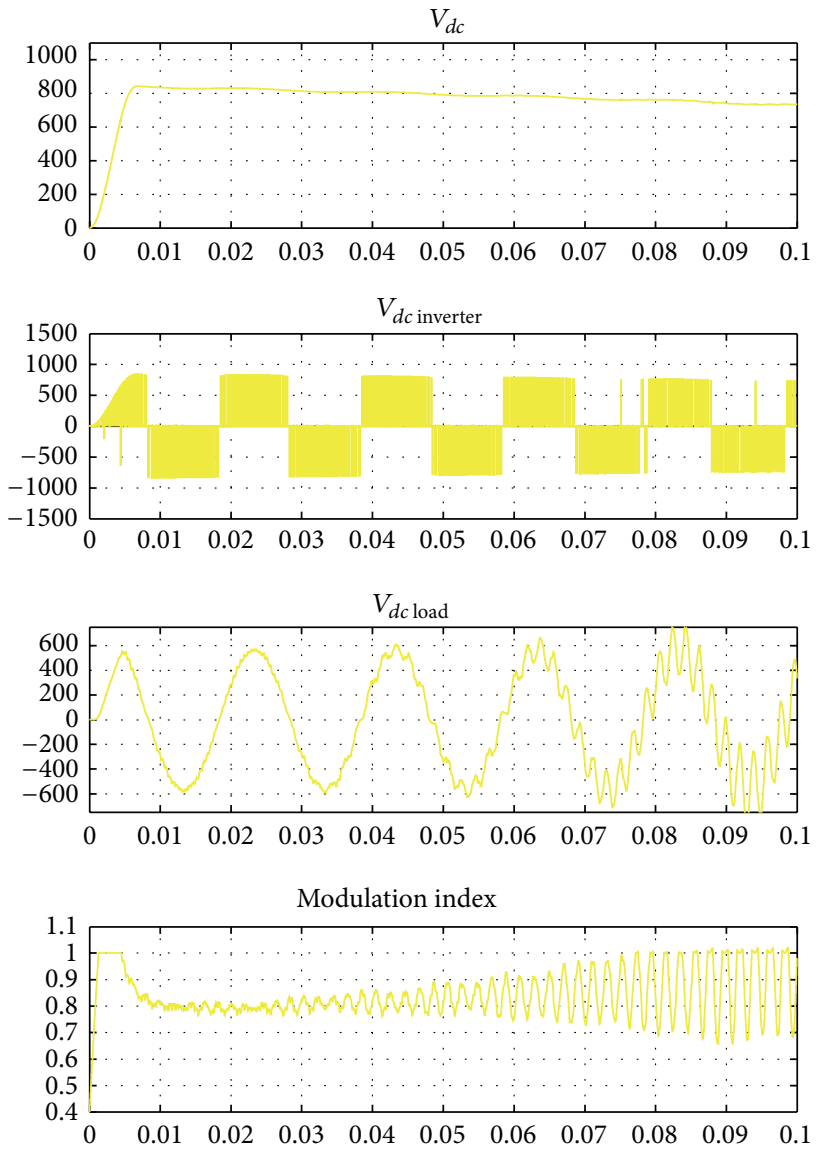

Time offset: 0
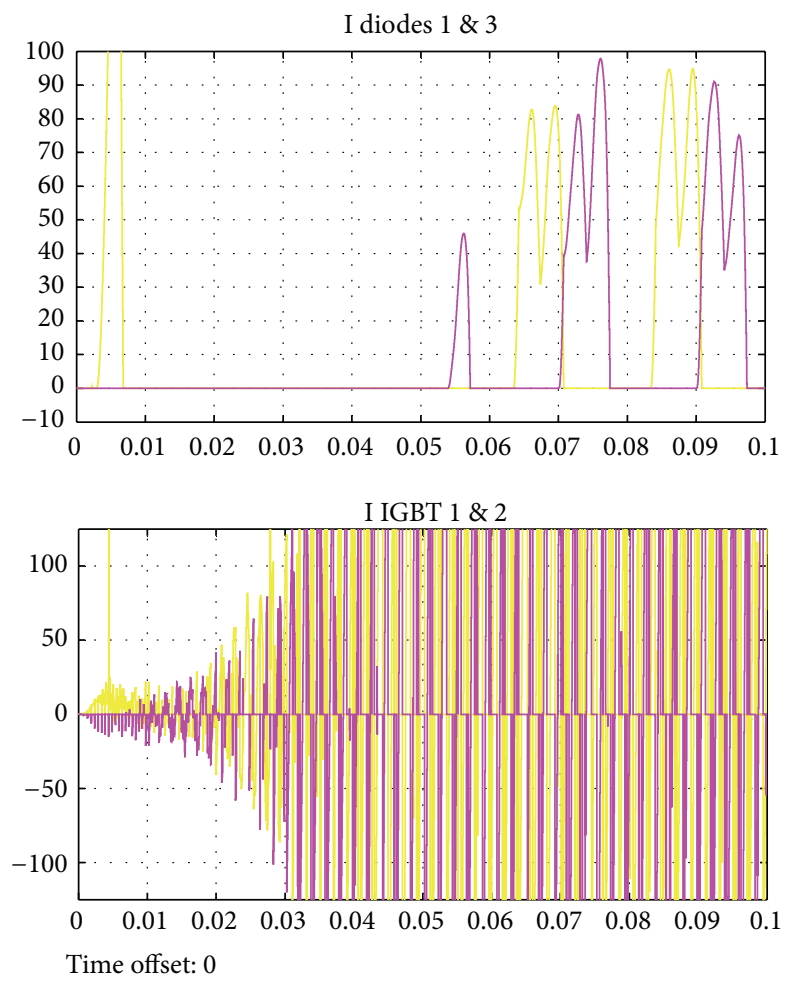

(a)

(b)

FIGURE 8: Induction machine $P=4 \mathrm{~kW}, \cos \varphi=0.53$ : (a) voltage diagram, (b) diode currents. 

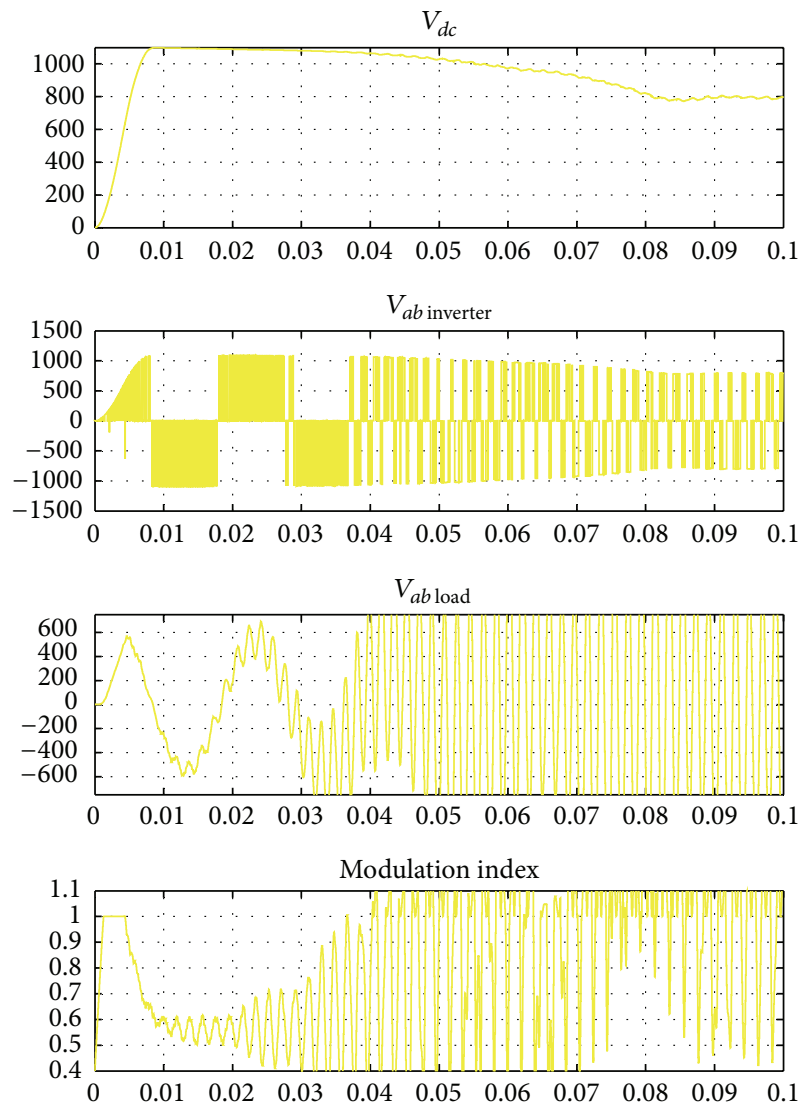

Time offset: 0
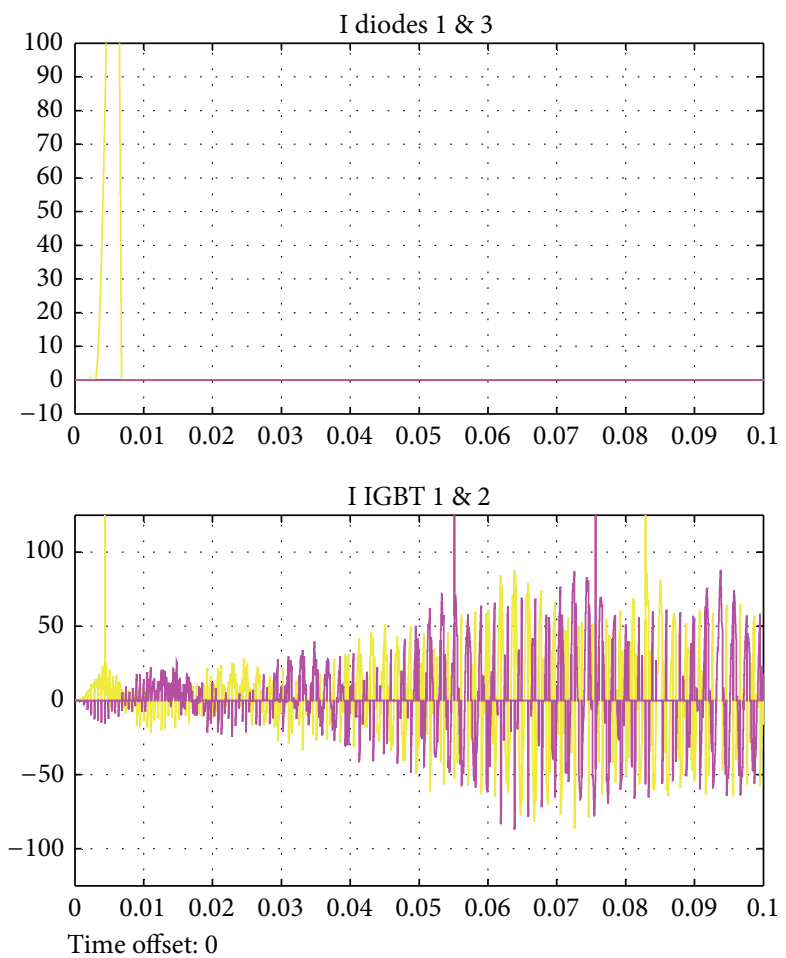

(a)

(b)

Figure 9: Induction machine $P=4 \mathrm{~kW}, \cos \varphi=1$ : (a) voltage diagram, (b) diode currents.

For $\lambda=120^{\circ}$ and $\omega R_{\text {load }} C \geq 1.51$ the scheme is the same as for $\lambda=180^{\circ}$ (Figure 4(a)), but instead of valve $V_{5}$ the diode $V_{5}^{\prime}$ is open. Current is determined by expressions (28).

The form of phase voltage changes at changing of value $\omega R_{\text {load }} C$. For $\lambda=120^{\circ}$ and $\omega R_{H} C \geq 1.51$ inverter scheme is given in Figure 4(b) where current is

$$
i_{A}=-i_{B}=\frac{V_{d}}{R_{\text {load }}(1+b)} e^{-\delta t}, \quad i_{C}=0 .
$$

The diagrams of load current at $\lambda=180^{\circ}$ and $\lambda=120^{\circ}$ are given on Figures 5(a) and 5(b). In the interval $0 \leq v \leq 180^{\circ}$ in Figure 5(a) and interval $0 \leq v \leq 120^{\circ}$ in Figure 5(b) the current flows through operating thyristors (two-operational) and in the interval $-60 \leq v \leq 0$ through inverse diodes.

In the three-phase inverter (the coupling of three single phase inverters which is widely used) (Figure 6), the valves are controlled by the angle of $120^{\circ}$. The load can be star and delta connected, through the transformer with separate phases or without such a transformer.

During the analysis of electromagnetic processes in threephase invertors it is considered that the system of voltage is symmetrical and output transformer ideal (the losses of dissipation and magnetizing currents are neglected), and transmission ratio is $n=N_{2} / N_{1}=1$. The assumptions practically do not affect the accuracy of the obtained expressions but make them simple.

\section{The Simulation Results}

For simulation and verification of the proposed model, the procedure known in the literature [13, 19] is used. The panel with the simulation scheme for the purpose of verification of the model is presented in Figure 7. It encompasses the rectifier for feeding of IGBT inverter through the DC link. PWM converter produces three-phase sinusoidal system of variable voltage and variable frequency for the load feeding. Three-phase inverter operates at a frequency of $2000 \mathrm{~Hz}$ and modulation frequency of $50 \mathrm{~Hz}$ [20].

Description of Blocks. Bridge block is implemented into universal three-phase power transducer and contains 6 power breakers connected into the bridge, and structure of the transducer is selected from the dialog box package.

The Dialog Box and Parameters of Configuration Channel. Group $A B C$ as input terminals connect $A, B$, and $C$ phases of the bridge at the input channels 1, 2, and 3 of the Universal Bridge Block. 

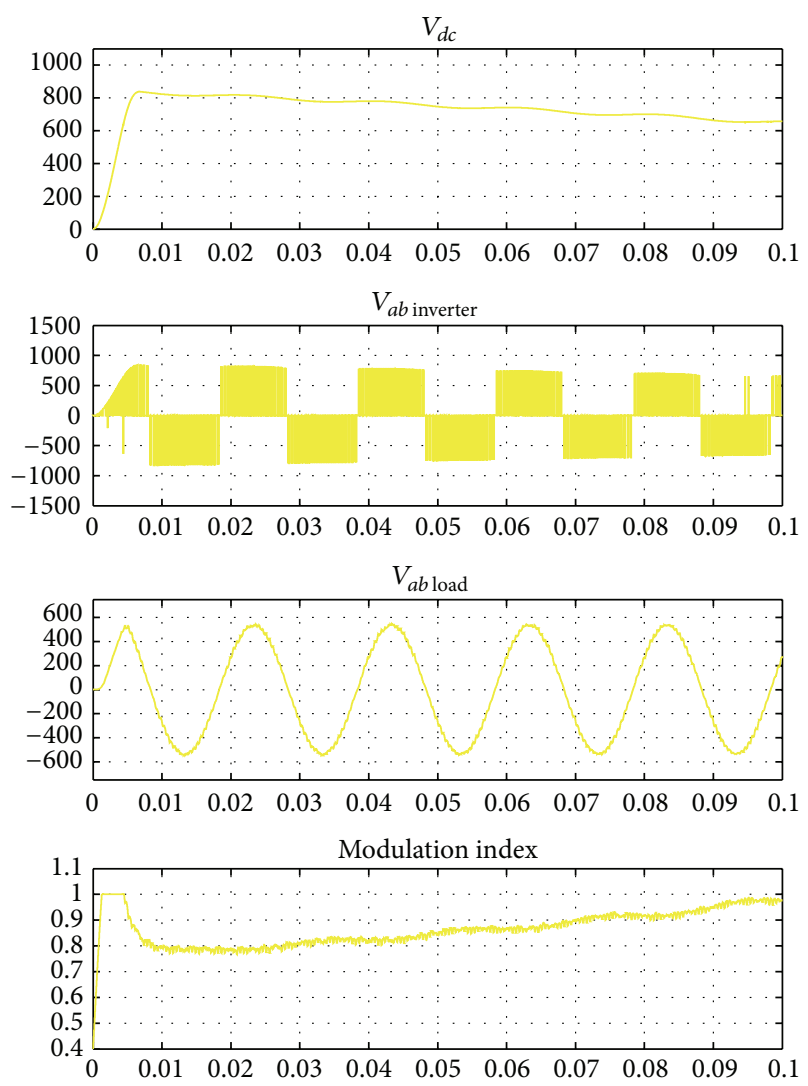

Time offset: 0
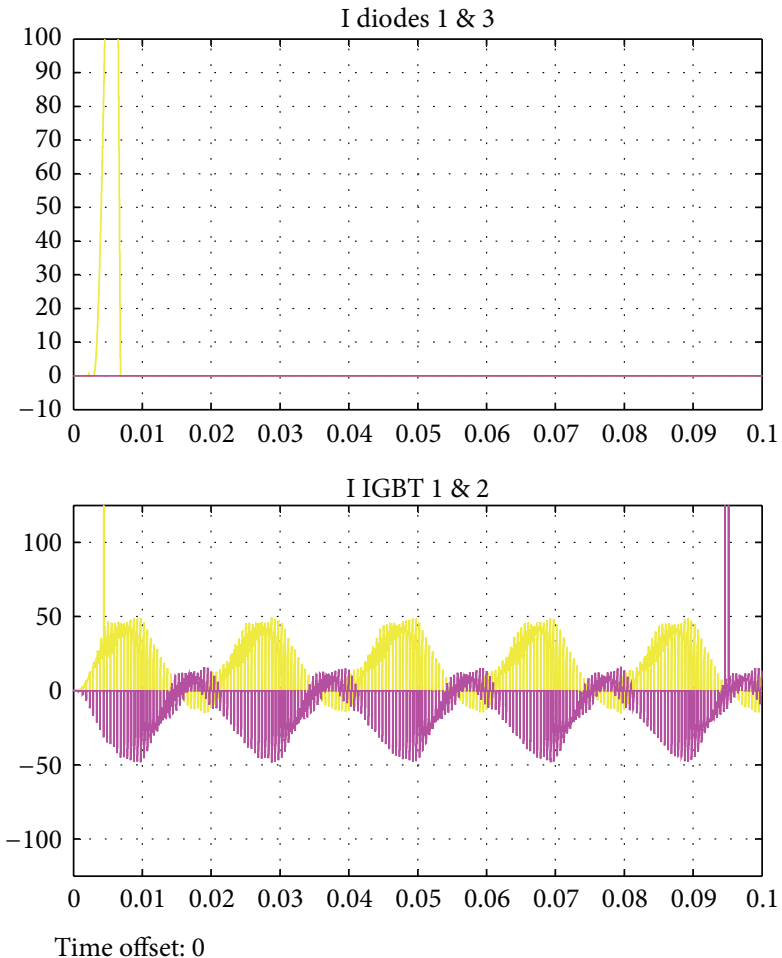

(a)

(b)

FIgURE 10: Induction machine $P=15 \mathrm{~kW}, \cos \varphi=0.53$ : (a) voltage diagram, (b) diode currents.

Damped resistance is $R s=100 \Omega$; damped capacitance is $C s=0.1 e^{-6} \mu \mathrm{F}$. When parameter of resistance is $R s=$ inf. $(\infty)$ the damping from the model is eliminated. If the capacitance parameter is $C s=0$ the damping from the model is eliminated, or if it is inf. ( $\infty)$ the active damping is obtained. The internal resistance of the selected device is $R_{\text {on }}=1 e^{-3} \Omega$, and the internal inductance is $L_{\text {on }}=0 \mathrm{H}$ for diodes, thyristors, or MOSFET devices. The time of signal declination is je $T_{f}=1 e^{-6} \mathrm{~s}$, and the time of signal end is $T_{t}=2 e^{-6} \mathrm{~s}$ both for GTO or IGBT devices.

The Device of Power Electronics. The type of the device of power electronics which shall be used in the bride is selected.

Measurements. The selected devices for measurement of the voltages are connected to 6 terminals of power electronics. The selected devices measure currents that flow through the 6 devices of power electronics. If damping devices are defined, the measurements of the current are the same for all individual currents that flow through the devices of power electronics. Selection of voltages $V_{a b}, V_{b c}, U_{c a}, U_{d c}$ is used for measurement of voltages at the derivatives (AC and $\mathrm{DC}$ ) of the Universal Bridge Block.
Simulation. After the transient period of approximately $70 \mathrm{~ms}$, the system achieves the steady-state. The wave forms of DC connection, output of the inverter, and the loop in Scope 1 are recorded. Harmonics generated in the inverter of about $2 \mathrm{kHz}$ are filtered on $L C$ filter. The expected voltage amplitude on the load is $537 \mathrm{~V}$ ( $380 \mathrm{~V}$ of effective value). In the steady-state regime the average value of modulation index is $m=0.77$, and the mean value of DC voltage is $780 \mathrm{~V}$.

The inverter creates the basic component of the voltage $(50 \mathrm{~Hz})$ by commutation; therefore $V_{a b}=780 \mathrm{~V} * 0.641 *$ $0.80=382 \mathrm{~V}$. The observed diode currents on the route 1/Scope 2 show the commutation from diode 1 to diode 3. The currents in breakers 1 and 2 of IGBT/Diode Bridge (higher and lower breaker activate the phase $A$ ) are shown in route $2 / S$ cope 2 . These two currents are complementary: positive current shows that current flows through IGBT, while negative current shows that current flows through antipanel diode. Scope 1 contains voltage on diodes $V_{d c}$, inverter voltage $V_{a b}$, load voltage $V_{\text {load }}$, and modulation index.

For the selected type of motor whose data are presented in Table 1 and known feeding voltage the optimal type of the inverter has been determined, with which it is possible to achieve required corrections regarding the power factor and power of the motor. Figure 7 presents the adapted scheme of 

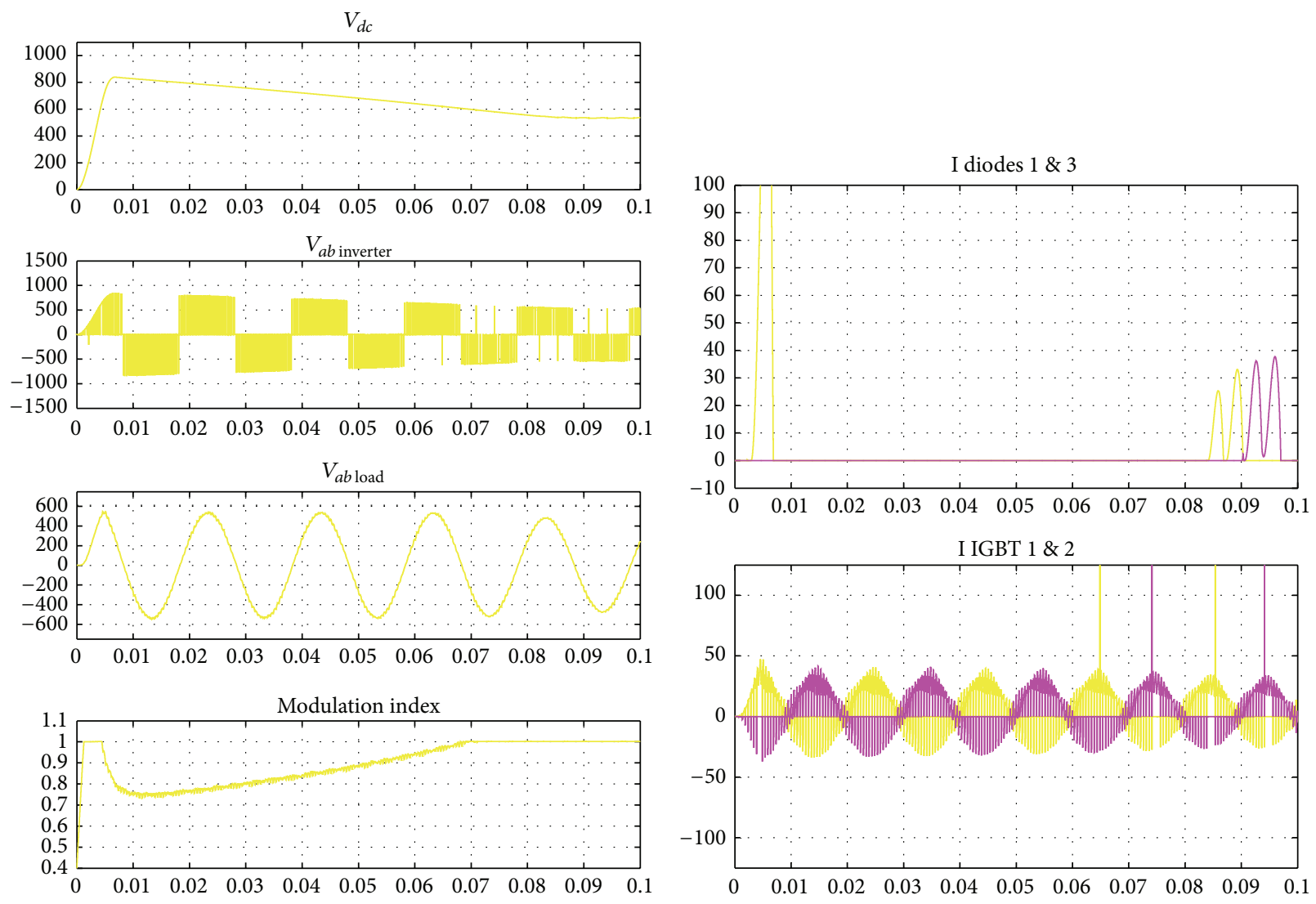

Time offset: 0

(a)

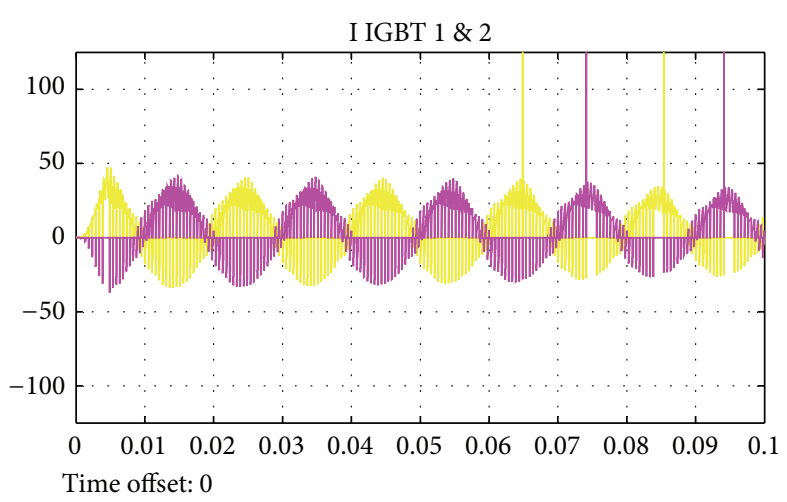

(b)

FIgURE 11: Induction machine $P=15 \mathrm{~kW}, \cos \varphi=1$ : (a) voltage diagram, (b) diode currents.

TABLE 1: Data on low-voltage three-phase closed motor with squirrel-cage rotor, http://www.sever.co.rs/.

\begin{tabular}{lccc}
\hline Tag & 2ZK112M-4 & 1ZK225S-4 & 1ZK225S-4 \\
\hline$P \mathrm{~kW}$ & 4 & 15 & 37 \\
$I_{n} \mathrm{~A}$ & 8,6 & 30 & 70 \\
$\min ^{-1}$ & 1420 & 1440 & 1470 \\
\hline
\end{tabular}

the simulation model of the induction motor operation, with the following characteristics: $\Delta$-coupling of stator winding, voltage $V=400 \mathrm{~V}$, power $P=(4,15$ and 37$) \mathrm{kW}$, power factor $\cos \varphi=0.53 ; 1$ and appropriate speed of rotation $n=(1420$, $1440,1470) \mathrm{min}^{-1}$ fed by PWM converter.

In the adapted part of the MATLAB simulation program package psbbridges.mdl demo by changing the power factor and nominal load power, the transient state model was verified in which the two mentioned parameters of the assembly at given voltage system of feeding which originates from the electric network are implemented. For the simulated values of the voltage from the feeding source the required waveforms of the corrected voltage are determined:

(i) at diodes $V_{d c}$,

(ii) at IGBT inverter $V_{a b}$, (iii) at $R-L$ load (induction motor) $V_{\text {load }}$,

(iv) at currents of diode and IGBT in inverter.

All waveforms are presented in Figures 8-13 as follows:

(i) Figure 8: (a) voltage diagram, (b) diagram of diode current for induction motor with power $P=4 \mathrm{~kW}$ and power factor $\cos \varphi=0.53$,

(ii) Figure 9: (a) voltage diagram, (b) diagram of diode current for induction motor with power $P=4 \mathrm{~kW}$ and power factor $\cos \varphi=1$,

(iii) Figure 10: (a) voltage diagram, (b) diagram of diode current for induction motor with power $P=15 \mathrm{~kW}$ and power factor $\cos \varphi=0.53$,

(iv) Figure 11: (a) voltage diagram, (b) diagram of diode current for induction motor with power $P=15 \mathrm{~kW}$ and power factor $\cos \varphi=1$,

(v) Figure 12: (a) voltage diagram, (b) diagram of diode current for induction motor with power $P=37 \mathrm{~kW}$ and power factor $\cos \varphi=0.53$,

(vi) Figure 13: (a) voltage diagram, (b) diagram of diode current for induction motor with power $P=37 \mathrm{~kW}$ and power factor $\cos \varphi=1$. 

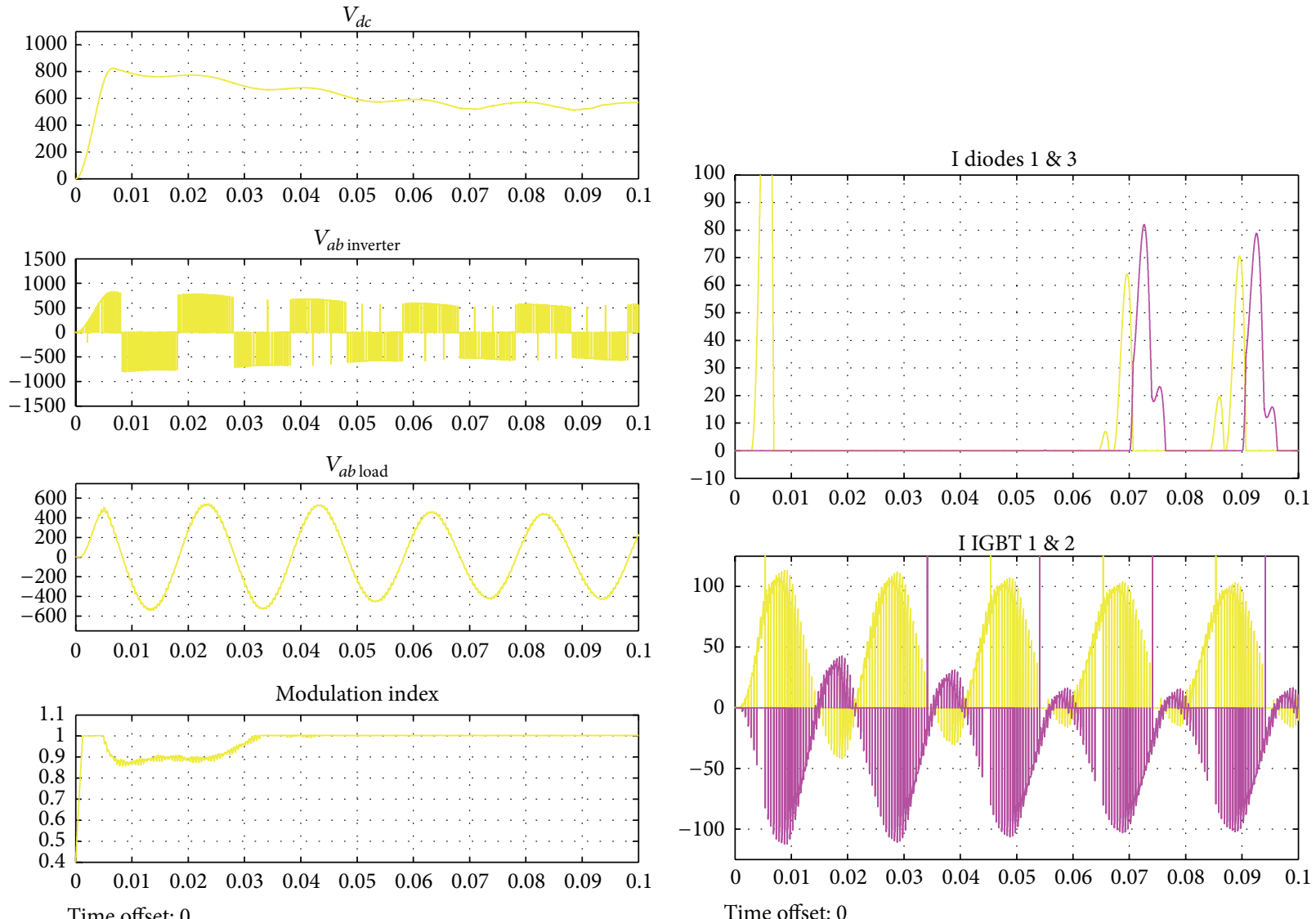

(a)

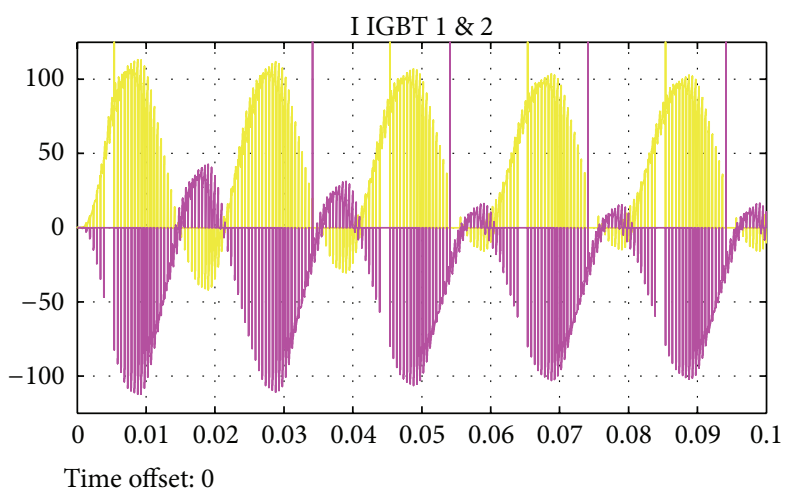

(b)

FIgURE 12: Induction machine $P=37 \mathrm{~kW}, \cos \varphi=0.53$ : (a) voltage diagram, (b) diode currents.

In all examples of the simulation, the induction motor had limited power of the inverter $P=50 \mathrm{~kW}$ which was sufficient for the testing since the greatest power of the motor was $P_{\text {induction machine }}=37.5 \mathrm{~kW}<P_{\text {inverter }}=50 \mathrm{~kW}$. The forms of time dependence, that is, diagrams of voltages and current, show that there is a significant impact of powers and power factors of the induction motor on the operation of the inverter.

In such a way the validity of the derived relation (21) was confirmed for the values of the current within the limits of the power factors of the induction motors $0.53 \leq \cos \varphi_{\text {load }} \leq$ 1.0. The validity and applicability of all derived formulas from (22) to (27), which are simple in form, were also verified.

The method which relies on the set-up differential equations and the inserted boundary conditions for each time interval of the operation corresponds to the research related to the analysis of the transient states of the induction machines to which voltage correctors are attached during the power supply process. The inverse Laplace transform is applied to the familiar form of the phase current in a circuit.

The new procedure based on derived algorithm calculations of the induction machine transient process is verified through diagrams in Figures 8, 9, 10, 11, 12, and 13. The current flow through the inverse diode time change leads to phase and line current changes. The phase and line currents remain unchanged only if $\lambda=180^{\circ}$. As evidenced, if the three-phase inverter feeds the induction motor (ohm's law inductive load) and if $\lambda=180^{\circ}$, the form of the current and the changing schema of the commutation intervals do not depend upon the load power factors. However, if $\lambda=120^{\circ}$ the form of the current depends upon the power factors and for $0.53 \leq \cos \varphi_{\text {load }} \leq 1.0$, the changing schema presented in Figures 3(c) and 3(d) changes its structure. In this way, the mathematical model of the three-phase bridge converter transient state whose active-inductive load is an induction machine is verified and different conditions of the induction machine operation with the changed load parameters, that is, power factor values of 0.53 in 1 , are analyzed.

\section{Conclusion}

The results obtained in the simulation procedure show that it is possible to accomplish the idea to present the induction motor as the active-inductive $(R L)$ load in mathematical model of the three-phase bridge inverters system, three-phase induction motor.

A part of the software package MATLAB-psbbridges.mdl demo that illustrates the use of dual Universal Bridge Block in AC-DC-AC converter has been used for verification of the model, which includes rectifier that feeds IGBT inverter through DC link. PWM converter provides three-phase 

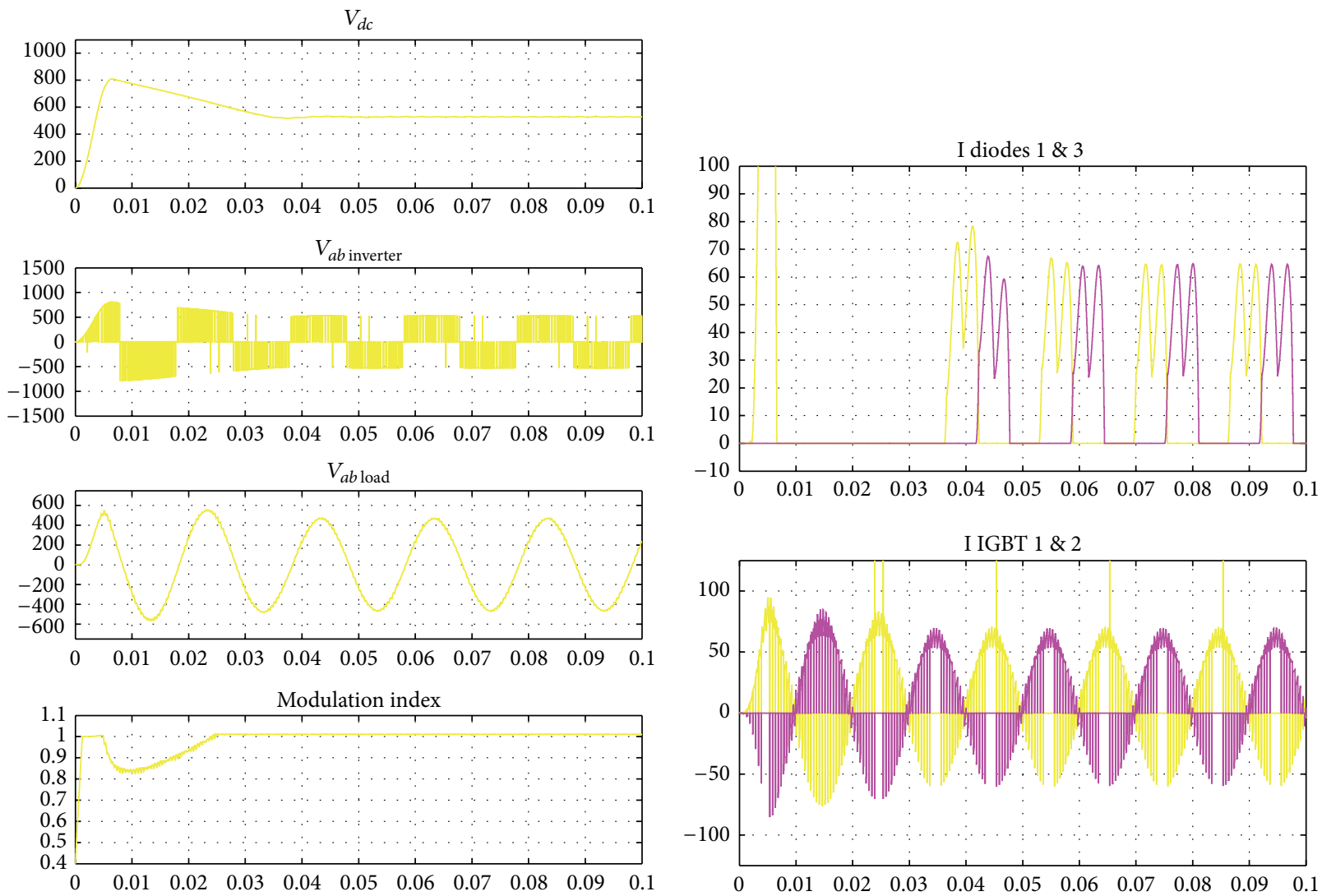

Time offset: 0

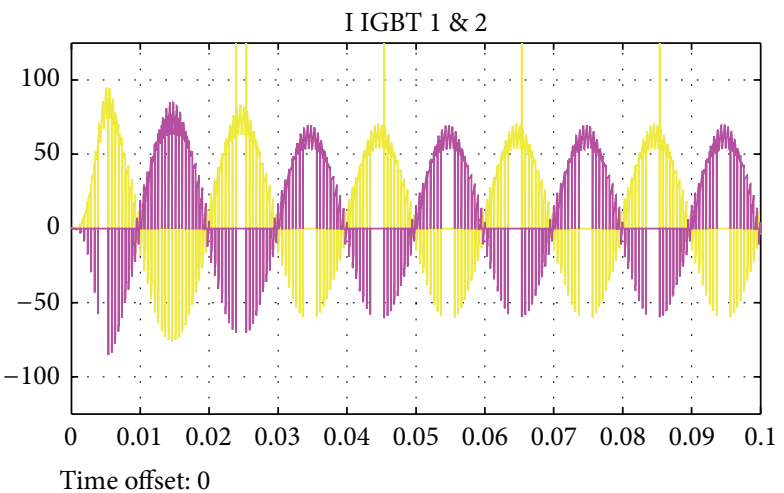

(a)

(b)

Figure 13: Induction machine $P=37 \mathrm{~kW}, \cos \varphi=1$ : (a) voltage diagram, (b) diode currents.

sinusoidal system of voltage and variable frequency for feeding of the load.

The induction motors of different powers and power factors are tested for the purpose of the model verification. The behavior of the inverter with the selected parameters of the load and the verification of the theoretical model is derived by 3-type 2-pole induction motor "Sever," with motor delta coupling $\Delta=D$ and with power factor $\cos \varphi=$ $0.53 ; 1$.

Values of voltage of direct circuit, interphase voltages, modulation indices, currents of diode, and IGBT inverter have been measured. When the power loads are less than $10 \%$ of the power of the inverter or when the power factors are low (0.53), in the simulation significant distortions on all sizes of the assembly were recorded. The assembly inverterinduction machine with respect to feeding network behaves like generator of higher harmonics: efficiency of correction of asymmetry to load was also reduced.

The obtained results indicate the possibility of application of converters for correction of asymmetries and elimination of harmonics.

Diagrams of voltages and currents show that there is a significant impact of powers and power factors of the induction motor on the operation of the inverter. This confirms the validity of the formulas relating to electrical quantities of the induction motor and inverter and takes into account the limits in regard to the power factors of the induction motors.

At the end of the paper the possibility of modelling the operation of the inverter and the induction motor was presented, where the induction motor was treated as the symmetrical-passive $R-C$ (ohm-capacitance) load, but due to the volume of the paper such simulation shall be presented in some of the following papers.

\section{Competing Interests}

The authors declare that there is no conflict of interests regarding the publication of this paper.

\section{References}

[1] E. R. Benedict and T. A. Lipo, "Improved PWM modulation for a permanent-split capacitor motor," in Proceedings of the Conference Record of the IEEE Industry Applications Conference, vol. 3, pp. 2004-2010, Rome, Italy, 2000.

[2] S.-G. Jeong and M.-H. Woo, "DSP-based active power filter with predictive current control," IEEE Transactions on Industrial Electronics, vol. 44, no. 3, pp. 329-336, 1997.

[3] P. Chlebis, P. Simonik, and M. Kabasta, "The comparison of direct and indirect matrix converters," in PIERS Proceedings, pp. 310-313, Cambridge, Mass, USA, July 2010. 
[4] H. Su and M. Z. Chen, "Multi-agent containment control with input saturation on switching topologies," IET Control Theory \& Applications, vol. 9, no. 3, pp. 399-409, 2015.

[5] C. Suciu, M. Kansara, P. Holmes, and W. Szabo, "Performance enhancement of an induction motor by secondary impedance control," IEEE Transactions on Energy Conversion, vol. 17, no. 2, pp. 211-216, 2002.

[6] S. Kim and P. N. Enjeti, "Control strategies for active power filter in three-phase four-wire systems," in Proceedings of the 15th Annual IEEE Applied Power Electronics Conference \& Exposition (APEC '00), vol. 1, pp. 420-426, Piscataway, NJ, USA, February 2000.

[7] M. Aredes, J. Hafner, and K. Heumann, "A three-phase fourwire shunt active filter using six IGBTs," in Proceedings of the 6th European Conference on Power Electronics and Applications (EPE '95), vol. 1, pp. 874-879, Seville, Spain, September 1995.

[8] H. Akagi, A. Nabae, and S. Atoh, "Control strategy of active power filters using multiple voltage-source PWM converters," IEEE Transactions on Industry Applications, vol. 22, no. 3, pp. 460-465, 1986.

[9] M. Aredes and E. H. Watanabe, "New control algorithms for series and shunt three-phase four-wire active power filters," IEEE Transactions on Power Delivery, vol. 10, no. 3, pp. 16491656, 1995.

[10] P. Verdelho and G. D. Marques, "An active power filter and unbalanced current compensator," IEEE Transactions on Industrial Electronics, vol. 44, no. 3, pp. 321-328, 1997.

[11] N. Marković, S. Bjelić, U. Jakšić, and M. Vujičić, "Development of new measuring systems based on symmetric components in electric networks," Elektronika ir Elektrotechnika, vol. 8, no. 104, pp. 57-62, 2010.

[12] M. Stanculescu, M. Maricaru, V. Stefan-Minculete, S. Marinescu, and I. F. Hantila, "Analytical solution for eddy current problem, using space eigen functions expansion," Revue Roumaine des Sciences Techniques-Serie Électrotechnique et Énergétique, vol. 58, no. 2, pp. 123-134, 2013.

[13] B. Singh, V. Verma, A. Chandra, and K. Al-Haddad, "Hybrid filters for power quality improvement," IEEE ProceedingsGeneration, Transmission and Distribution, vol. 152, no. 3, pp. 365-378, 2005.

[14] S. Bjelić, N. Marković, and J. Živanić, "One analytical method for calculation of converter-rectifier parameters and verification with tested simulation," http://www.irmbor.co.rs/images/ izdavastvo/casopisi/arhinovacije/inovacije2_13.pdf.

[15] L. A. Moran, L. Fernandez, J. W. Dixon, and R. Wallace, "A simple and low-cost control strategy for active power filters connected in cascade," IEEE Transactions on Industrial Electronics, vol. 44, no. 5, pp. 621-629, 1997.

[16] V. M. Cardenas, C. Nunez, and N. Vazquez, "Analysis and evaluation of control techniques for active power filters: sliding mode control and proportional-integral control," in Proceedings of the 14th Annual Applied Power Electronics Conference and Exposition (APEC '99), vol. 1, pp. 649-654, Dallas, Tex, USA, March 1999.

[17] S. Bjelić, U. Jakšić, and N. Marković, Energetski pretvarači, Quark-Kraljevo, 2010, http://www.vbs.rs/cobiss/cobiss_sr-en .htm.

[18] J. Dixon, J. J. Garcia, and L. Moran, "Control system for threephase active power filter which simultaneously compensates power factor and unbalanced loads," IEEE Transactions on Industrial Electronics, vol. 42, no. 6, pp. 636-641, 1995.
[19] H. Akagi, "Active harmonic filters," Proceedings of the IEEE, vol. 93, no. 12, pp. 2128-2141, 2005.

[20] S. Sunter, M. Ozdemir, and B. Gumus, "Modelling and simulation of single phase induction motor with adjustable switched capacitor," in Proceedings of the 9th International Conference on Power Electronics and Motion Control (EPE-PEMC'00), pp. 5-15-5, Kosice, Slovakia, 2000. 


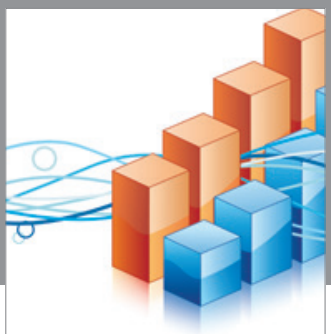

Advances in

Operations Research

vatem alat4

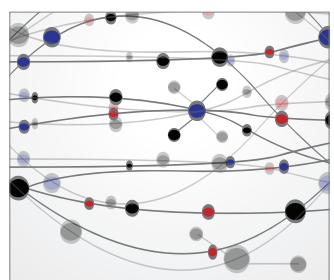

\section{The Scientific} World Journal
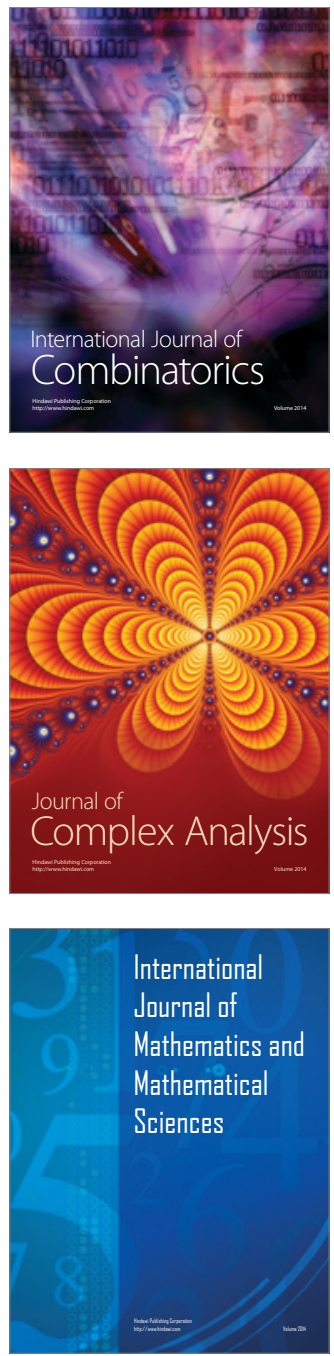
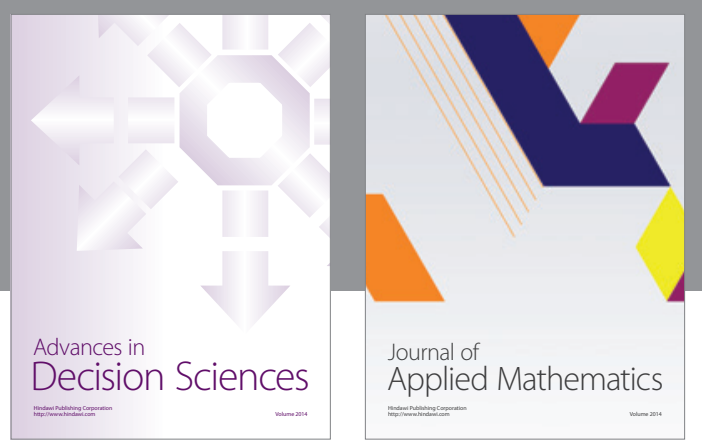

Algebra

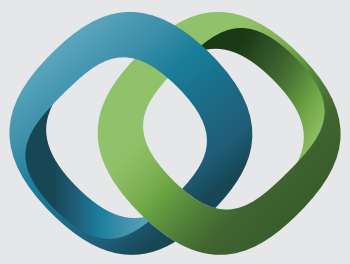

\section{Hindawi}

Submit your manuscripts at

http://www.hindawi.com
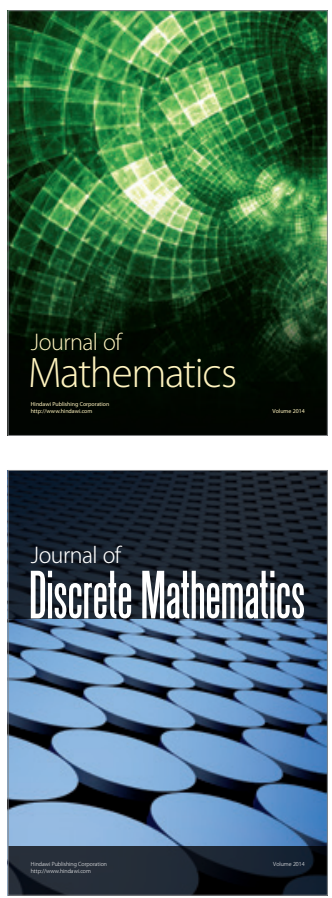

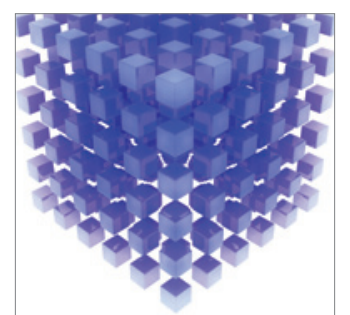

Mathematical Problems in Engineering
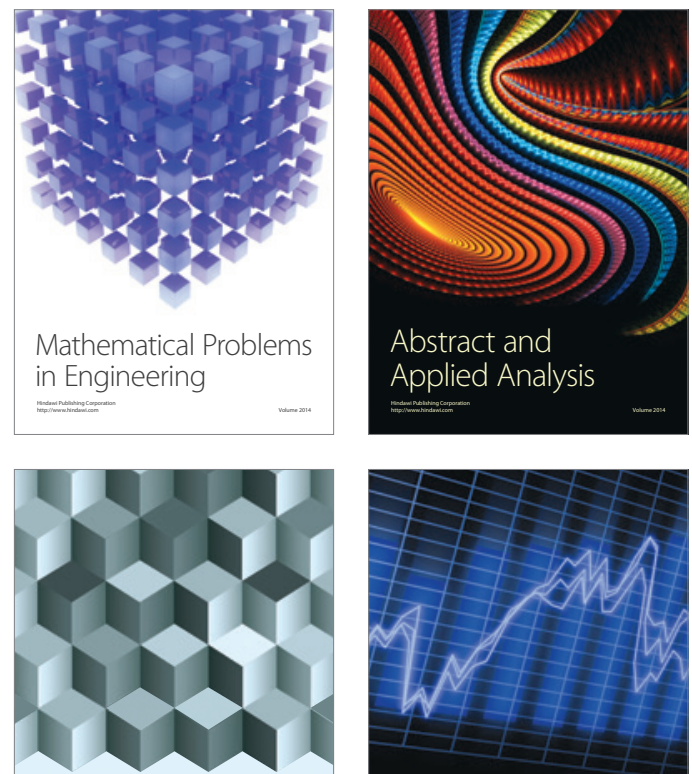

Journal of

Function Spaces

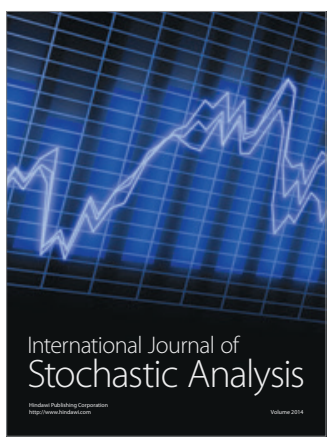

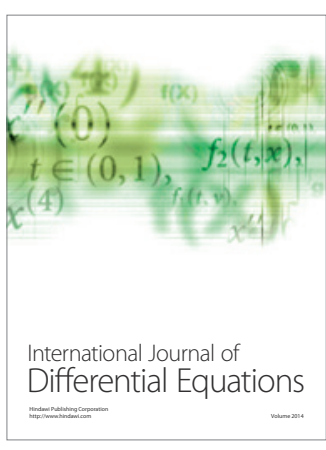
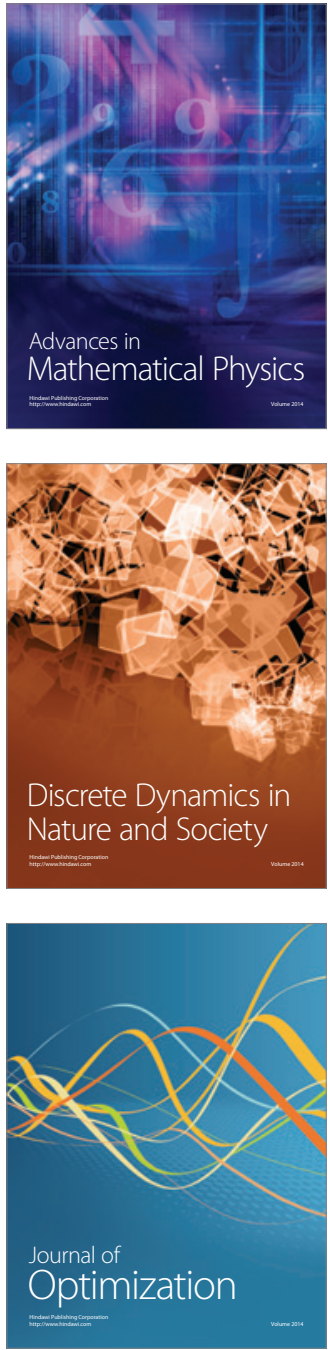